\title{
NATURE OF INDIVIDUAL DIFFERENCE IN LIABILITY TO DEPRESSION IN RUSSIAN ADOLESCENTS
}

\author{
Alexandra P. Belova, \\ Elena Z. Sabirova, \\ Sergey B. Malykh \\ Psychological Institute of Russian Academy of Education \\ Moscow, Russia
}

The Influence of genetic and environmental factors on liability to depression in Russian teenage sample was investigated. 196 twin pairs aged 13 to $17(M=15,2)$ from Moscow, lzhevsk and Bishkek took part in the survey. We have found out that genetic factors had an effect on individual difference in depressiveness among Russian teenagers: more than $50 \%$ of variance was explained by additive genetic factors which correspond to international results. The biggest genetic influence was obtained for such scales as negative emotions, negative self esteem and externalization which are the most replicable factor scales in CDI structure worldwide.

Keywords: behavioral genetics, twin study, depression, teenagers, Children depression inventory (CDI).

Depression is the most widespread emotional disturbance virtually worldwide (in Eastern and Western Europe, the USA). Moreover, the number of people suffering from depression continues to grow. According to population studies, 10 to $15 \%$ of males and $20-30 \%$ of females experience a depression episode at least once in a lifetime (Hell, 1999; Weissman, Wolk et al., 1999). It should be noted that the main contributors to growth of depressiveness are teenagers and youngsters (Weissman, Wolk et al., 1999). Depression may emerge as a reaction to a stressful life event or a psychological trauma (death of significant others, life failures, etc.); depression frequently develops for no apparent cause, though. Depending on severity of its course, depression can have a clinical nature (clinical depression) or be limited to manifestations that rather lie in the competence of psychologists. Recent years have seen a number of papers 
investigating depressiveness as an individual trait, specifically in childhood and adolescence. What is understood under depressiveness in this instance is the susceptibility of a person to have depressive experience in a variety of situations. In contrast to clinical depression, which is identified via medical criteria, subclinical depressiveness is usually measured with specially designed questionnaires. Psychological studies show that about $70 \%$ of children who experienced depression manifestations keep on experiencing depressive episodes in their adult life, as well (Harrington et al., 1990). It is crucial to point out that emotional experiences can significantly worsen quality of life and even block normal mental growth in teenagers.

Apparently, understanding the origin of individual differences in such emotional characteristics as depressiveness ${ }^{1}$ is important both for enhancing efficiency of intervention measures (Mufson, Moreau, Weissman \& Klerman, 2003) as well as for defining a high-risk group, which, in its turn, offers opportunity for preventive measures.

The aim of our study was to evaluate the role of genetic and environmental factors on the origin of individual differences in susceptibility to depression in teenagers.

\section{Methods and sample}

Subjects. 196 twin pairs aged 13 to 17 (Mean age $=15.2)$ took part in the study. There were 72 pairs of monozygotic twins ( 32 pairs of boys and 40 pairs of girls), 81 pairs of dizygotic twin pairs (47 pairs of boys and 49 pairs of girls), and 43 opposite sex dizygotic twin pairs among them. The twin zygosity was identified by means of the polysymptom comparison method. All pairs with unclear zygosity were excluded from the analysis.

Psychodiagnostic methods. Children depression inventory (CDI; Kovacs, 2008) that had been pre-adapted and standardized on a Russian adolescent sample was used in this study. To provide standardization and psychometric check-up of the methods, an additional sample of singleborn children was employed. The standardization sample was composed

\footnotetext{
1 Depressiveness is understood as depressive experience in teenagers that has no clinical nature, though. This term was used by A.I. Podol'skij (Podol'skij, Idobaeva, \& Hejmans, 2004).
} 
of 713 teenagers aged 13 to 17 . Among them, there were 208 younger teenagers (13-14 years old) and 505 elder teenagers (15-17 years old) consisting of 335 boys and 378 girls.

Statistical analysis. Descriptive statistics was analyzed by means of a SPSS package.

Structural equation modeling was used to assess genetic and environmental factors contributed to individual differences in depressiveness (Neale \& Cardon, 1992). Structural equation modeling (also known as latent variables modeling) is a general approach assuming that genotypic and environmental influence is viewed as a contribution of nonmetering (latent) variables to individual phenotypic distinctions. The method is based on algorithms for selecting models of phenotypic variation and comparison of theoretical variation structure with its real structure in data.

$\mathrm{MZ}$ and DZ twins data are used to evaluate the impact of the following factors on general phenotypical variability: additive (A) and non-additive (D) genetic factors; non-genetic factors, which enhance similarity between sibs, that can be called a "common environment" (C); non-genetic factors, which reduce similarity between sibs, that can be called "individual environment" (E). The last component further includes variance caused by a measurement error (pic. 1).

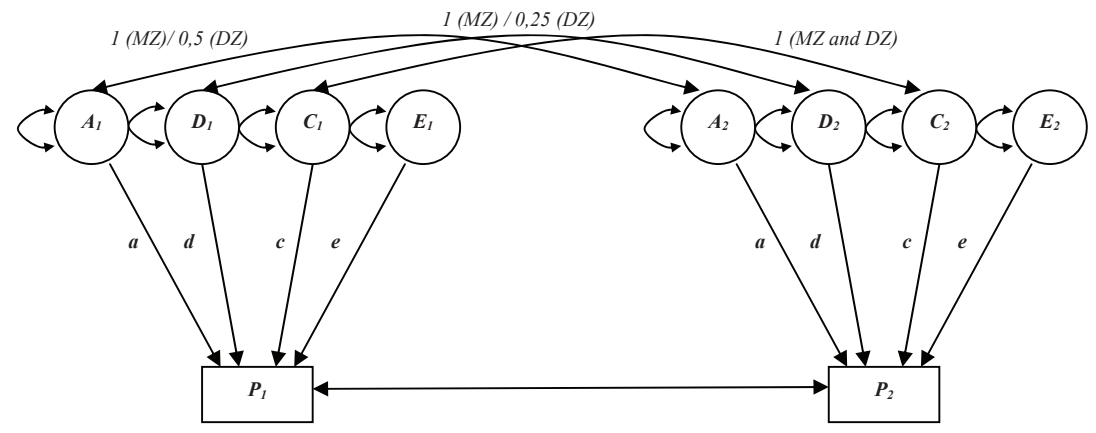

Pic. 1. Path coefficients diagram. Rectangles represent measurable variables; circles represent latent variables; one-way arrows (or paths) show hypothetic causal relationships between variables; two-way arrows show covariances and dispersions. 
A variant of the full-information maximum likelihood method was applied to evaluate compliance of the model with data. The choice of an optimal model was guided in each case by the following logarithmic likelihood criteria: $-2 \mathrm{LnL}$, with statistics being distributed as a $\chi$ square function, the $\chi$ square function, and the Akaike information criterion (AIC). Four models of a variance structure were tested with respect to each of the indices under investigation: the full ACE model (which includes only genetic factors and individual environment); the simple AE genetic model (which includes only genetic factors and individual environment); the $\mathbf{C E}$ environmental model (which includes only common and individual environment); and the $\mathbf{E}$ random effects model (which includes only individual environment and measurement error).

\section{Results and discussion}

\section{Psychometric characteristics of the questionnaire (reliability of measurements)}

The symptoms mentioned by $\mathrm{M}$. Kovacs were compared with the symptoms mentioned in MKB-10 and Russian-language psychological literature in connection with teenage depressiveness prior to adapting the methods to a Russian sample (Kovacs, 2008). The results of said comparison highlighted the need for adding a variant of a negative emotional state typical of teenagers suffering from depression (irritation) described in Russian literature as an extra question ${ }^{2}$.

Estimated correlation with composite score was provided for each question, with the alpha index having been calculated for each question deleted from the questionnaire. Upon this procedure, the question "I'm sure something bad is going to happen to me" was excluded, since it had a poor correlation to the composite score and gave no response dispersion. The Cronbach's alpha appeared to be considerably high (alpha = 0.874) for the complete version of the modified questionnaire consisting

\footnotetext{
2 Apart from this statement, 3 more questions pertaining to such cognitive disorders as memory difficulties, ease of concentration, and overeating, which can serve as manifestations of depression in teenagers as demonstrated by the relevant literature, were included in the questionnaire. However, the last 3 questions revealed weak concordance with depressiveness on the whole (it might be due to the fact that they can often be features of absolutely different traits and conditions, as well) in the preliminary step of the study and hence they were excluded from further consideration.
} 
of 27 items, which shows high scale uniformity. An average score against the sum of 27 questions initially included in the CDI method, along with a composite score according to the modified CDI method, was calculated to compare our results with data obtained from other researches. The comparison results are represented in Table 1.

Table 1

\begin{tabular}{|c|c|c|c|c|c|c|}
\hline & \multicolumn{2}{|c|}{$\begin{array}{c}\text { Twenge J.M., } \\
\text { meta-analysis } \\
\text { of 310 studies } \\
\text { (age 13-16) }\end{array}$} & \multicolumn{2}{|c|}{$\begin{array}{c}\text { Russian sample, } \\
\text { 27 original Kovacs } \\
\text { questions } \\
\text { (age 13-17) }\end{array}$} & \multicolumn{2}{|c|}{$\begin{array}{c}\text { Russian sample, } \\
\text { modified CDI } \\
\text { questionnaire } \\
\text { (age 13-17) }\end{array}$} \\
\hline & Boys & Girls & Boys & Girls & Boys & Girls \\
\hline Mean & 8.9 & 10.1 & 9.0 & 9.4 & 10.1 & 10.9 \\
\hline Std. Deviation & - & - & 4.7 & 5.0 & 6.3 & 5.7 \\
\hline
\end{tabular}

Although the age boundaries were slightly broader in our study, the table demonstrates that the data obtained on the Russian-speaking sample using the original Kovacs questions do not differ noticeably from the data obtained by J.M. Twenge after the meta-analysis of 310 studies through said method (Kovacs, 2008; Twenge \& Nolen-Hoeksema, 2002).

The factor analysis of modified CDI was carried out by applying the maximum likelihood method with Promax rotation. 6 factors were revealed as a result, although one of them appeared to be trivial. Therefore, the final solution consisted of 5 factors that in total could explain mere $27 \%$ of the response dispersion, which is similar to the results obtained by other researchers.

The following five scales were described: negative emotionality $($ alpha $=0.71)$; negative self esteem $($ alpha $=0.68)$; anhedonia including reluctance to communicate (alpha $=0.58$ ); externalization (linked to such manifestations as "I do not do what I am asked to do", "I fall out with people all the time", "People around me are dissatisfied with me"). This turned out to have relatively low reliability $(\mathrm{alpha}=0.454)$; somatic manifestations (which included only two items: "I always feel tired" and "There is always something in me that hurts") (alpha $=0.53)$.

3 Mean values for boys and girls aged 13-16 were calculated according to the means published by J.M. Twenge for each age separately. 
It worth noticing that our study, like studies on other cultures, revealed three "obligatory" CDI factors associated with depressiveness in teenagers. These factors include negative emotionality, low self esteem, and externalization, where the first two factors proved to be the most reliable.

Moreover, we found two additional factors that are mentioned by other authors, that is anhedonia and reluctance to communicate, and somatic manifestations.

At the same time, the above-discussed scales explain only $30 \%$ of variance and hence caution should be addressed to them. For this reason a reliable cumulative index is used for the analysis.

Twin pairs cross correlations analysis

Twin correlations for each variable in MZ and DZ (same sex and opposite sex) twin pairs were calculated for each measured variable (depressiveness total score and each of the scales). The results are shown in Table 2.

Table 2

Cross correlations on depressiveness scores in MZ and DZ twins

\begin{tabular}{|c|c|c|c|c|c|c|}
\hline \multirow{2}{*}{} & \multicolumn{2}{|c|}{ MZ twins } & \multicolumn{2}{c|}{$\begin{array}{c}\text { DZ same sex } \\
\text { twins }\end{array}$} & \multicolumn{2}{c|}{$\begin{array}{c}\text { DZ opposite sex } \\
\text { twins }\end{array}$} \\
\cline { 2 - 7 } & $\mathrm{r}$ & $p$ & $\mathrm{r}$ & $P$ & $\mathrm{r}$ & $P$ \\
\hline Total CDI score & .49 & .00 & .41 & .00 & .40 & .00 \\
\hline Negative emotions & .54 & .00 & .43 & .00 & .41 & .00 \\
\hline Negative self esteem & .42 & .00 & .38 & .00 & .37 & .00 \\
\hline Externalization & .45 & .00 & .27 & .00 & .28 & .00 \\
\hline Somatic manifestations & .07 & .57 & .18 & .02 & .11 & .10 \\
\hline Anhedonia & .33 & .01 & .33 & .00 & .32 & .00 \\
\hline
\end{tabular}

Table 2 clearly demonstrates that responses of both MZ and DZ twins are similar in terms of all the characteristics measured (cross correlations are statistically significant in most cases). The somatic manifestations scale was the only exception, for which cross correlations in MZ and opposite sex DZ twins appeared to be insignificant. The foregoing 
may be connected with characteristics of the scale itself, which consists of 2 items and manifests a rather low internal reliability. Therefore, this scale was excluded from further analysis.

As for the total CDI score, cross correlations of the MZ twins are higher that cross correlations of DZ twins which may be a sign of potential genetic influence. This is true for such separate CDI scales as negative emotions, negative self esteem, and externalization, too. The correlations were equal across $\mathrm{MZ}$ and $\mathrm{DZ}$ twins for the anhedonia and reluctance to communicate scale, which rather means environmental influence on scores of this scale.

\section{Model fitting}

We checked four models of a phenotypic dispersion structure for each tested variable: ACE full model, AE genetic model, CE environmental model, and E random effects model. Since MZ twins correlations never were more than twice as high as $\mathrm{DZ}$ twins correlations, the ADE model comprising nonadditive genetic factors (D) was not applied. Likewise, once correlations between opposite sex DZ twins and same sex DZ twins were not considerably different for variables that were likely to be genetically affected, we did not resort to genetic models including influence of the sex variable. The model fitting results are set out in Table 3.

According to the modeling results, the AE genetic model characterized by strong influence of the genetic factor $(\mathrm{A}=.57 ; \mathrm{E}=.43)$ turned out to be the best fit for total CDI score. The same model was suitable for the negative emotions $(A=.61 ; E=.39)$ and the externalization $(A=$ $.38 ; \mathrm{E}=.62$ ) scales. These results are very much in line with the results that were received on teenage samples in other countries (e.g. Scourfield et al., 2003; Thapar\&McGuffin, 1994). The ACE full model, in which around a half of individual differences is explained by random factors together with individual environment, and genetic and common environment factors each explain $25 \%$ of the variance $(\mathrm{A}=.25 ; \mathrm{C}=.2 ; \mathrm{E}=.55)$, showed the best fit for the negative self esteem scale. About a half of all differences were explained by individual environment, while genetic and common environmental factors contributed for about $25 \%$ each. Variance on the anhedonia and reluctance to communicate scale was best explained by the $\mathrm{CE}$ environmental model $(\mathrm{C}=.33 ; \mathrm{E}=.67)$. 
Model fitting results for depressiveness scores

Table 3

\begin{tabular}{|c|c|c|c|c|c|c|c|c|c|c|}
\hline & \multirow[t]{2}{*}{$\begin{array}{l}\text { Mo- } \\
\text { del }\end{array}$} & \multicolumn{2}{|c|}{$\begin{array}{l}\text { A (additive } \\
\text { genetic } \\
\text { factors) }\end{array}$} & \multicolumn{2}{|c|}{$\begin{array}{l}\mathrm{C} \text { (common } \\
\text { environment } \\
\text { factors) }\end{array}$} & \multicolumn{2}{|c|}{$\begin{array}{l}\text { E (individual } \\
\text { environment } \\
\text { factors) }\end{array}$} & \multicolumn{3}{|c|}{$\begin{array}{c}\text { Model } \\
\text { characteristics }\end{array}$} \\
\hline & & A & \begin{tabular}{|c} 
conf. \\
Inter- \\
val
\end{tabular} & $\mathrm{C}$ & $\begin{array}{l}\text { conf. } \\
\text { Inter- } \\
\text { val }\end{array}$ & $\mathbf{E}$ & $\begin{array}{c}\text { conf. } \\
\text { inter- } \\
\text { val }\end{array}$ & $-\mathbf{L} 2 \mathrm{~L}$ & $A I C$ & $\mathrm{p}$ \\
\hline $\begin{array}{l}\text { CDI total } \\
\text { score }\end{array}$ & $\mathrm{AE}$ & .57 & $\begin{array}{l}.39- \\
.70\end{array}$ & - & - & .43 & $\begin{array}{l}.29- \\
.61 \\
\end{array}$ & 861 & 261 & .61 \\
\hline $\begin{array}{l}\text { Negative } \\
\text { emotionality }\end{array}$ & $\mathrm{AE}$ & .61 & $\begin{array}{l}.45- \\
.73\end{array}$ & - & - & .39 & $\begin{array}{l}.27- \\
.55\end{array}$ & 889 & 259 & .62 \\
\hline $\begin{array}{l}\text { Negative self } \\
\text { esteem }\end{array}$ & ACE & .25 & $0-.60$ & .20 & $0-.47$ & .55 & $\begin{array}{l}.40- \\
.76\end{array}$ & 903 & 265 & .77 \\
\hline $\begin{array}{l}\text { Externali- } \\
\text { zation }\end{array}$ & $\mathrm{AE}$ & .38 & $\begin{array}{l}.20- \\
.54\end{array}$ & - & - & .62 & $\begin{array}{l}.46- \\
.80\end{array}$ & 921 & 275 & .99 \\
\hline $\begin{array}{l}\text { Somatic ma- } \\
\text { nifestations }\end{array}$ & \multicolumn{10}{|c|}{ No model fits. A model cannot be selected. } \\
\hline Anhedonia & $\mathrm{CE}$ & - & - & .33 & $\begin{array}{l}.18- \\
.46\end{array}$ & .67 & $\begin{array}{l}.54- \\
.82\end{array}$ & 913 & 291 & .77 \\
\hline
\end{tabular}

\section{Conclusion}

Thus, the results of our study obtained on the Russian teenage sample proved to be mainly consistent with reference data according to which genetic factors make a weighty contribution to the formation of susceptibility to depressiveness among teenagers. For example, similar results were announced by A. Thapar and P. McGuffin in 1994 (Thapar \& McGuffin, 1994). They reported that additive genetic influence on individual depressiveness distinctions among teenagers aged 12-16 was .76 if depressiveness was evaluated according to teenagers' responses and .78 if it was based on responses submitted by their parents. J. Scourfield et al (2003) achieved similar results: the additive genetic component was .8 for 12-17 year-old girls and .68 for boys. F. Rice et al studied children aged 11-17 (Rice, Harold, \& Thapar, 2005) and found sufficient influence of the additive genetic factor $(\mathrm{a}=.45)$.

It is worth mentioning that the main genetic influence was demonstrated for those scales of the questionnaire that were consistently identified almost in all CDI method-related studies, namely, negative emo- 
tions, negative self esteem and externalization. On the one hand, it may provide further support for substantiated isolation of these factors; on the other hand, it explicitly shows that distinctions of emotional reaction are closely connected with genetic susceptibility. Simultaneously, such indices as reluctance to communicate and anhedonia largely depend on specific traits of the environment a teenager lives in.

\section{Acknowledgments}

This study was supported by grant GK № 14.740.11.0882 from Ministry of Education and Science of the Russian Federation.

\section{References}

Harrington, R., Fudge, H., Rutter, M., Pickles, A., \& Hill, J. (1990). Adult outcomes of childhood and adolescent depression. Archives of General Psychiatry, 47, 465-473.

Hell, D. (1999). Landshaft depressii [Ethologie der Depression]. Moscow: Aleteja.

Kovacs, M. (2008, copyright 1992, 2003). Children's Depression Inventory (CDI). Technical Manual Update. Toronto: Multi-Health Systems, Inc.

Mufson, L., Moreau, D., Weissman, M., \& Klerman, G. (2003). Podrostok i depressiya. Mezhlichnostnaya psihoterapiya [Interpersonal Psychotherapy for Depressed Adolescents] Moscow: Jeksmo.

Neale, M.C., \& Cardon, L.R. (1992). Methodology for genetic studies of twins and families. Norwood, MA: Kluwer Academic.

Podol'skij, A.I., Idobaeva, O.A., \& Hejmans, P. (2004). Diagnostika podrostkovoj depressivnosti. Teoriya i praktika [Diagnostics of adolescent depression. Theory and practice]. St. Petersburg: Piter.

Rice, F., Harold, G.T., \& Thapar, A. (2005). The link between Depression in mothers and offsprings: an extended twin analysis. Behavior Genetics, 35(5), 565-577.

Scourfield, J., Rice, F., Thapar A., Harold, G.T., Martin, N., \& McGuffin, P. (2003). Depressive symptoms in children and adolescents: Changing aetiological influences with development. Journal of Child Psychology and Psychiatry, 44, 968-976.

Thapar, A., \& McGuffin, P. (1994). A twin study of depressive symptoms in childhood. British Journal of Psychiatry, 165(2), 259-265.

Twenge, J.M., \& Nolen-Hoeksema, S. (2002). Age, Gender, Race, Socioeconomic Status, and Birth Cohort Differences on the Children's Depression Inventory: A MetaAnalysis. Journal of Abnormal Psychology,111(4), 578-588.

Weissman, M.M., Wolk, S., Wickramaratne, P., Goldstein, R.B., Adams, P., Greenwald, S., Ryan, N., Dahl, R.E., \& Steinberg, D. (1999). Children with prepubertal-onset major depressive disorder grown up. Archives of General Psychiatry, 56, 794-801. 